\title{
Axoplasm Enriched in a Protein Mobilized by Nerve Injury Induces Memory-Like Alterations in Aplysia Neurons
}

\author{
Richard T. Ambron, ${ }^{1}$ Michael F. Dulin, ${ }^{2}$ Xiao-Ping Zhang, ${ }^{1}$ Robert Schmied, ${ }^{1}$ and Edgar T. Walters ${ }^{2}$ \\ ${ }^{1}$ Departments of Anatomy and Cell Biology, Columbia University, New York, New York 10032, and ${ }^{2}$ Physiology and \\ Cell Biology, University of Texas Medical School, Houston, Texas 77225
}

\begin{abstract}
Axon regeneration after injury and long-term alterations associated with learning both require protein synthesis in the neuronal cell body, but the signals that initiate these changes are largely unknown. Direct evidence that axonal injury activates molecular signals in the axon was obtained by injecting axoplasm from crushed or uncrushed nerves into somata of sensory neurons with uncrushed axons. Those injected with crush axoplasm behaved as if their axons had been crushed, exhibiting increases in both repetitive firing and spike duration, and a decrease in spike afterhyperpolarization $1 \mathrm{~d}$ after injection. Because similar changes occur in the same cells after learning, these data suggest that some of the long-lasting adaptive changes that occur after injury and learning may be induced by common axoplasmic signals. Since the signals in axoplasm must be conveyed to the cell soma, we have begun to test the hypothesis that at least some of these signals are proteins containing a nuclear localization signal (NLS). Axoplasmic proteins at the crush site and those that accumulated at a ligation proximal to the crush were probed with an antibody to an amino acid sequence (sp) containing a NLS that provides access to the retrograde transport/nuclear import pathway. One protein, sp97, displayed properties expected of an axonal injury signal: it responded to injury by undergoing an anterograde-to-retrograde change in movement and, when the ligation was omitted, it was transported to the cell bodies of the injured neurons.
\end{abstract}

[Key words: retrograde axonal transport, injury signals, axotomy, excitability, sensitization, nuclear import, learning]

A central issue in the search for therapies that promote the repair of injured nerves concerns the identity of the signals that initiate the repair process. Since axons have a limited capability for synthesizing macromolecules, most proteins required for axon extension and reinnervation must be supplied by the biosynthetic centers in the cell soma. How is information from the site of injury, which can be a great distance from the cell body, conveyed back to the nucleus to initiate these changes? While this

\footnotetext{
Received Aug. 10, 1994: revised Nov. 7, 1994; accepted Nov. 10, 1994.

We thank Dr. Andrew Osipov, John Gunstream, and Michael Povelones for help with some of the experiments, and Jim Pastore for illustrations. This work was supported by NIH Grant NS-12250 and NS-22638 to R.T.A., and NSF Grant IBN-9210268 and NIMH Grant MH38726 to E.T.W.

Correspondence should be addressed to Richard T. Ambron, Ph.D., DepartInent of Anatomy and Cell Biology, Columbia University, W. 168th Street, New York, NY 10032.

Copyright 1995 Society for Neuroscience $0270-6474 / 95 / 153440-07 \$ 05.00 / 0$
}

question is posed within the context of injury, the occurrence of neuronal growth during learning (e.g., Bailey and Kandel, 1993) and the dependence of learning-related hyperexcitability on protein synthesis (Dale et al.. 1987) raise interesting general questions about cellular signaling systems that trigger long-lasting neuronal alterations in response to inputs remote from the soma. For example, are retrograde signaling systems that trigger regenerative growth after peripheral axon injury also used to initiate synaptic growth and changes in excitability after appropriate stimulation of remote synaptic terminals (see Clark and Kandel, 1993; Emptage and Carew, 1993)?

In principle, three classes of signals could inform the cell soma that the axon has been injured: (1) injury-evoked action potential discharge, (2) interruption of the retrograde transport of constitutive homeostatic signals from target tissues, and (3), the retrograde transport of molecular signals activated as a consequence of nerve injury. Although spike activity can regulate the transcription of certain immediate-early genes (Leah et al., 1991; Herdegen et al., 1992), this signal is not specific to injury (Sheng and Greenberg, 1990; Morgan and Curran, 1991; Vendrell et al., 1993) and is not necessary for adaptive reactions to axonal injury in neurons of the marine mollusk Aplysia (Walters et al., 1991; Gunstrcam ct al., 1994a). Likewise, injury-induced deprivation of trophic signals from peripheral targets or support cells may cause significant alterations in neuronal phenotype and gene expression (Nja and Purves, 1978; Wu et al., 1993), but the precise contribution of these widely discussed "negative" signals to the induction of long-term adaptive reactions of neurons to injury is unknown (Watson, 1968; Grafstein and Forman, 1980; Aldskogius et al., 1992; Traynor et al., 1992). Finally, a role for "positive" induction signals carried from the site of injury to the soma is an attractive idea that has long been postulated (Kristensson and Olsson, 1975; Bisby and Bulger, 1977), but has heen difficult to verify experimentally; evidence for the existence of such molecules therefore is indirect (Singer, 1982; Soiefer et al., 1988; Walters et al. 1991; Gunstream et al., 1994a). A pathway was recently discovered in Aplysia neurons that conveys soluble axoplasmic proteins via rapid retrograde transport through the axon to the cell body and then into the nucleus (Ambron et al., 1992; Schmied et al., 1993). It occurred to us that a protein signal generated by injury could conveniently use this pathway to get back to the nucleus. Proteins that use this pathway have a short amino acid sequence (signal peptide, sp) that, because it contains a nuclear localization signal (NLS), provides access to retrograde transport and nuclear import (Ambron et al., 1992; Schmied et al., 1993).

In the present study we have directly tested the hypothesis 
that positive molecular signals are activated in injured axons. First, we used alterations of sensory neuron soma excitability and spike duration as a monitor for long-lasting effects of somatic injection of axoplasm from crushed or uncrushed nerves. Second, using an antibody that recognizes the $s p$, we examined whether some axonal injury signals are NLS-containing proteins.

Some of these findings have been published in abstract form (Ambron et al., 1994; Walters et al., 1994).

\section{Materials and Methods}

Nerve crush and extrusion of axoplasm. Animals (75-200 gm), purchased from Marinus, Long Beach. CA, were maintained in aerated. filtered Instant Ocean (Aquarium Systems, Eastlake, $\mathrm{OH}$ ) with seaweed as food. In a typical experiment, the animal was anesthetized by injecting an isotonic solution of $\mathrm{MgCl}_{2}$ equivalent to one-third its body weight. The animal was suspended, head up, from a yoke so that the hemolymph pooled in the caudal regions. A $1 \mathrm{~cm}$ incision was made in the anterolateral body wall and nerves $p 7$ and $p 9$ were located. One nerve, selected randomly, was crushed $3 \mathrm{~cm}$ from the pedal ganglion with a number 5 forceps and then both nerves were ligated with a suture $1 \mathrm{~cm}$ from the ganglion. The incision was closed and the animal was placed in the aquarium. Twenty-four hours later, the CNS was removed and axoplasm in the $5 \mathrm{~mm}$ segment adjacent (distal) to the ligations was extruded into $50 \mu \mathrm{l}$ ice-cold iso-osmotic buffer (Sherbany et al., 1984; Schmied et al., 1993) without protease inhibitors. The extrudates from four to six ligations were combined. A sample was removed to determine total protein and, after concentrating to approximately $1 \mu \mathrm{g}$ protein $/ \mu \mathrm{l}$, the remainder was either stored at $-20^{\circ} \mathrm{C}$ for injection or was extracted with buffer containing SDS at $70^{\circ} \mathrm{C}$ for $20 \mathrm{~min}$.

Intrasomatic injection of axoplasm. After anesthetizing 150-300 gm animals by cooling to $4^{\circ} \mathrm{C}$ and injection of isotonic $\mathrm{MgCl}_{2}(50 \%$ of body weight), cach pair of pleural-pedal ganglia was excised, leaving all pedal nerves as long as possible so that axonal injury signals from the cut ends would not have time to get to the ganglia during the course of the experiment (see Gunstream et al., 1994a). The pleural ganglia were surgically desheathed in a 1:1 mixture of ASW and isotonic $\mathrm{MgCl}_{2}$. One hour after washing out the $\mathrm{MgCl}_{2}, 10-15$ sensory neuron cell bodies in each pleural ganglion were injected by pressure (two 10 msec pulses at 20 psi through unbeveled electrodes) with approximately $5 \mathrm{pl}$ of axoplasm ( $1 \mu \mathrm{g}$ protein/ $\mu \mathrm{l}$ ) and fast green in $1.0 \mu \mathrm{M}$ potassium phosphate buffer ( $\mathrm{pH}$ 7.6). One side received axoplasm from uncrushed nerves and the other, axoplasm from crushed nerves. The ganglia were then placed in a 1:1 mixture of culture medium $(\mathrm{pH} 7.5)$ and hemolymph.

Testing procedures were nearly identical to those used to measure the electrophysiological propertics of the sensory neuron soma after axonal injury in vivo (Walters et al., 1991; Clatworthy and Walters, 1994) and in vitro (Gunstream et al., 1994a). Briefly, intracellular recordings were made using glass microelectrodes filled with $3 \mathrm{~m}$ potassium acetate. Sensory neurons retaining green dye were sampled alternately in the left and right ganglia, pairing each neuron with a cell in the corresponding location in the contralateral cluster. Spike amplitude, duration, and afterhyperpolarization were examined by stimulating the cell through the recording electrode with a $2 \mathrm{msec}$ depolarizing pulse. Repetitive firing properties were assessed by counting the number of spikes elicited by a 1 sec depolarizing pulse. To separate changes in spike accommodation from changes in spike threshold, the current used in this 1-sec test stimulus was $1.25 \times$ or $2.5 \times$ the current required to reach spike threshold (see Table 1), which was determined beforehand with a standard 20 msec pulse (see Gunstream et al.,1994a). Input resistance of each cell was calculated from the voltage change produced by injecting a $1 \mathrm{sec}, 0.5 \mathrm{nA}$ hyperpolarizing pulse through the recording electrode (after rebalancing the bridge).

Statistical comparisons were made across animals with paired, twotailed $t$ tests. Four to eight injected cells were sampled successfully per cluster (with each cell paired with a sensory neuron in the contralateral cluster). The average values for each property per cluster were used as individual data points to compare cells injected with crush or control axoplasm.

SDS-PAGE and Western blotting. SDS extracts of equivalent amounts of axoplasmic protein from the various sources, or of sensory cell bodies with crushed or noncrushed nerves, were separated on $10 \%$ polyacrylamide slab gels (Ambron et al., 1992). The proteins were ei-

\begin{tabular}{|c|c|c|c|}
\hline Property & $\begin{array}{l}\text { Control } \\
\text { injection }\end{array}$ & $\begin{array}{l}\text { Crush } \\
\text { injection }\end{array}$ & $p$ \\
\hline \multicolumn{4}{|c|}{ Repetitive firing (\# of spikes) } \\
\hline $1.25 \times$ threshold & $1.6 \pm 0.2$ & $3.3 \pm 0.6$ & $0.004^{a h}$ \\
\hline $2.5 \times$ threshold & $4.2 \pm 0.3$ & $6.5 \pm 0.8$ & $0.002^{4,1 s}$ \\
\hline Threshold (nA) & $1.4 \pm 0.1$ & $1.4 \pm 0.1$ & $0.70^{m . h}$ \\
\hline AHP $(\mathrm{mV})$ & $4.6 \pm 0.5$ & $3.2 \pm 0.1$ & $0.02^{a . h}$ \\
\hline Spike amplitude (mV) & $87.0 \pm 2.2$ & $91.7 \pm 2.4$ & $0.09^{a}$ \\
\hline Spike duration (msec) & $2.6 \pm 0.1$ & $3.1 \pm 0.2$ & $0.02^{a, i s}$ \\
\hline Input resistance $(\mathrm{M} \Omega$ ) & $29.3 \pm 2.8$ & $34.1 \pm 4.4$ & 0.30 \\
\hline Resting potential (mV) & $45.9 \pm 1.0$ & $47.8 \pm 1.4$ & 0.25 \\
\hline
\end{tabular}

Statistics are for seven animals (paired, two-tailed $t$ tests). Each animal contributed a mean value for control and crush properties based on measurements from four to six pairs of sensury aleurons.

"Previously shown to be altered after in vivo nerve crush

"Previously shown to be altered after learning.

ther visualized by silver staining or were translented to nitrocellulose, which was probed with the affinity-purified anti-sp antibody $(1: 300)$ (Ambron et al., 1992; Schmied et al., 1993). The antibody can detect as little as $3 \mathrm{ng}$ of protein. In some experiments, serial dilutions of axoplasm were made to achieve the optimum ratio of antigen to antibody. Some blots were developed using a chemiluminescent assay (Kierkegard \& Perry, Gaithersburg, MD).

Protein phosphorylation in response to injury. The right and left pleuropedal ganglia, each with the maximal lengths of $\mathrm{p} 7$ and $\mathrm{p}^{9}$ attached, were removed from the animal and placed in a $0.5 \mathrm{~cm}$ well containing phosphate-free medium. The nerves were threaded through a vaseline gap into another chamber containing artificial seawater (ASW). Carrier-free $32 \mathrm{P},(150 \mu \mathrm{Ci})$ (Dupont, Boston, MA) was added to the central well. This procedure labels the intraganglionic pools of ATP (Bernier et al., 1982). Eighteen hours later, which is enough tinte for radiolabeled ATP to move several centimeters along the nerves, the medium in the central well was replaced with ASW. Both nerves were ligated $0.5 \mathrm{~cm}$ from the ganglion, and then one nerve was crushed 2 $\mathrm{cm}$ more distally. After an additional $24 \mathrm{hr}$ at $15^{\circ} \mathrm{C}$, the $5 \mathrm{~mm}$ segment of nerve on the distal side of each ligation was removed, extracted into hot SDS, and equal cpm were subjected to SDS-PAGE and autoradiography.

\section{Results}

\section{Axoplasm from crushed nerves induces long-term hyperexcitability when injected into neurons}

To test the hypothesis that axoplasm from injured nerves contains positive molecular signals that trigger long-term alterations of the neuron, we injected axoplasm from crushed and uncrushed nerves into somata of nociceptive mechanosensory neurons in the ventrocaudal (VC) cluster of each pleural ganglion (Walters et al., 1983a). The 200 or so sensory neurons in each VC cluster send axons via the pedal nerves to innervate most of the ipsilateral body surface (Walters et al., 1983a; Dulin et al., 1994). Axoplasm for injection was obtained using a simple ligation paradigm (Fig. 1). Peripheral nerves $p 7$ and $p 9$ were exposed through an incision in the neck. One nerve was crushed and then both were ligated close to the pedal ganglion. The incision was sutured and the animal was returned to its aquarium. Twenty-four hours later axoplasm was extruded from the 5 $\mathrm{mm}$ segment on the distal side of each ligation; this segment is enriched in proteins that have been retrogradely transported (Fig. 1, retro).

Extrudates from four to six similarly treated nerves were combined, and a small amount from crushed nerves was injected 
Figure 1. Diagram showing nerve crush site, ligation sites, and sensory neuron somata. The regions of the nerve that were removed for the extrusion of axoplasm are indicated. Relationships are not drawn to scale. Retrodistal side of the ligation, which accumulates retrogradely transported material. Antero-proximal side of the crush, which accumulates anterogradely transported material.

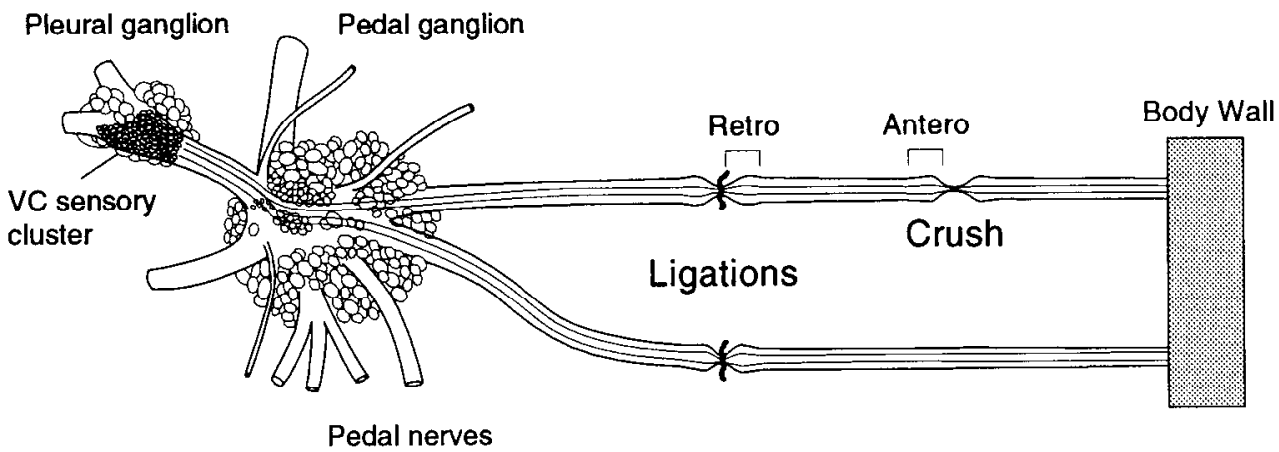

Pedal nerves with fast green dye into $10-15$ sensory neurons in one pleural sensory cluster. The same amount of control axoplasm and dye was injected into the same number of sensory neurons in the contralateral cluster. Eighteen to $20 \mathrm{hr}$ after injection, the marked neurons were impaled and tested with a standardized intracellular stimulation sequence that has revealed characteristic changes in soma excitability and action potential properties after axonal injury in vivo (Walters et al., 1991; Clatworthy and Walters, 1994) and in vitro (Gunstream et al., 1994a). As found after axonal injury, sensory neurons injected with axoplasm from crushed nerves exhibited significantly increased repetitive firing during prolonged depolarization compared to cells injected with axoplasm from uncrushed nerves (Fig. $2 A, B$; Table 1 ). The increase was not due to differences in the amount of current injected, since injected current was normalized to spike threshold, which was identical in each group. Sensory neurons injected with axoplasm from uncrushed nerves showed no significant difference in repetitive firing compared to sensory neurons that had not been injected (Fig. $2 B$ ). Injection of crush axoplasm also caused a significant increase in spike duration and decrease in magnitude of the afterhyperpolarization (AHP) (Fig. 2C, Table 1). Spike threshold, input resistance, and resting potential showed no significant alterations after crush axoplasm injection. Although the effect on spike amplitude was not significant using a two-tailed $t$-test, the low $p$ value for this result suggests a potential effect that should be examined further.

\section{Crush injury results in the retrograde transport of $s p 97$}

The injection experiments suggested that axoplasm from crushed nerves contains plasticity signals that are absent in axoplasm from nerves ligated in the absence of nerve crush. Reasoning that these signals might be proteins that contain the sp sequence, we used an affinity-purified antibody to the sp (Ambron et al. 1992) and compared axoplasm from crush/ligated and ligated nerves. Several sp-containing polypeptides were recognized on Western blots, and in three of four experiments, axoplasm at the ligation from the crushed nerves was markedly enriched in only one of several sp-polypeptides, sp97 (Fig. 3A). No differences were found when polypeptides in axoplasm from the two sources were compared by silver staining (not shown).

One interpretation consistent with these results is that $\operatorname{sp97}$ responds to a crush injury by undergoing an anterograde-to-retrograde shift in transport at the site of the lesion. Some proteins (Frizell et al., 1976; Bulger and Bisby, 1978; Smith and Snyder, 1991 ) and organelles (Schmidt et al., 1980; Smith, 1988) in vertebrate nerves behave this way. If so, then an enrichment in sp97 at the ligation should be accompanied by a reduction at the crush site. To test this idea, we crushed and ligated nerves as before, but extruded axoplasm from both the distal side of the ligation (retro, Fig. 1) and from the proximal side of the crush, which should accumulate anterogradely transported material (antero, Fig. 1). In all four experiments, involving a total of 20 nerves from eight animals, sp97 accumulated at the ligation, and was greatly reduced or absent at the crush site (Fig. $3 B$ ). In contrast, the content of $\operatorname{sp} 83$ and the other constituents was unchanged at the crush site. Their presence argues against the reduced amount of sp97 being due to an injury-induced general proteolysis.

We next wondered whether sp97 would be transported all the way to the cell body if the ligation were omitted. To investigate this possibility, we took advantage of the fact that the pedal nerves contain axons from the pleural mechanosensory neurons (Fig. 1). We crushed the nerves $0.5 \mathrm{~cm}$ from the sensory cell cluster, excised the nervous system, and placed it in a supplemented seawater (Eisenstadt et al., 1974). One day later, the somata in the sensory cluster were removed and combined. An equal number of sensory somata were removed from nervous systems whose axons were not crushed. The two samples were then examined for their content of sp-containing proteins. We carried out two experiments, and in each, sensory neurons with crushed axons contained much more sp97 than did clusters whose axons were not crushed (Fig. 3C). There was no difference in the amount of sp83. Sp97 probably entered the nucleus of these cells because microinjection of proteins containing the sp sequence into Aplysia axons results in transport of the proteins to the soma and then import of the proteins into the nucleus (Ambron et al., 1992; Schmied et al., 1993).

Sp97 is phosphorylated after crush injury to peripheral nerves Both sp97 and $\mathrm{sp} 83$ contain the $\mathrm{sp}$, which mediates transport, yet only sp97 changed direction in response to the crush. This points to the reversal in transport as an important cvent, and prompted us to investigate what causes sp97 to move retrogradely. Some soluble proteins are rapidly transported through the axon via an association with the surface of vesicles (Greengard et al., 1993), and the association is often regulated by phosphorylation. To see if any proteins are phosphorylated in response to injury, the crush/ligation protocol was repeated with nervous tissue that had been exposed to ${ }^{32} \mathrm{P}_{\mathrm{i}}$ in vitro to label ATP (Bernier et al., 1982). In each of two experiments there was an increase in the phosphorylation of several polypeptides after crush, one of which corresponded to sp97 (Fig. 3D). In contrast, sp83 was not labeled. If phosphorylation leads to the retrograde mobilization of sp97, then the kinase(s) responsible for the phosphorylation would be a link between injury and the retrograde signaling system.

\section{Discussion}

Long-lasting reactions of neurons to peripheral injury require that signals from the axon reach the nucleus to alter protein 
A.
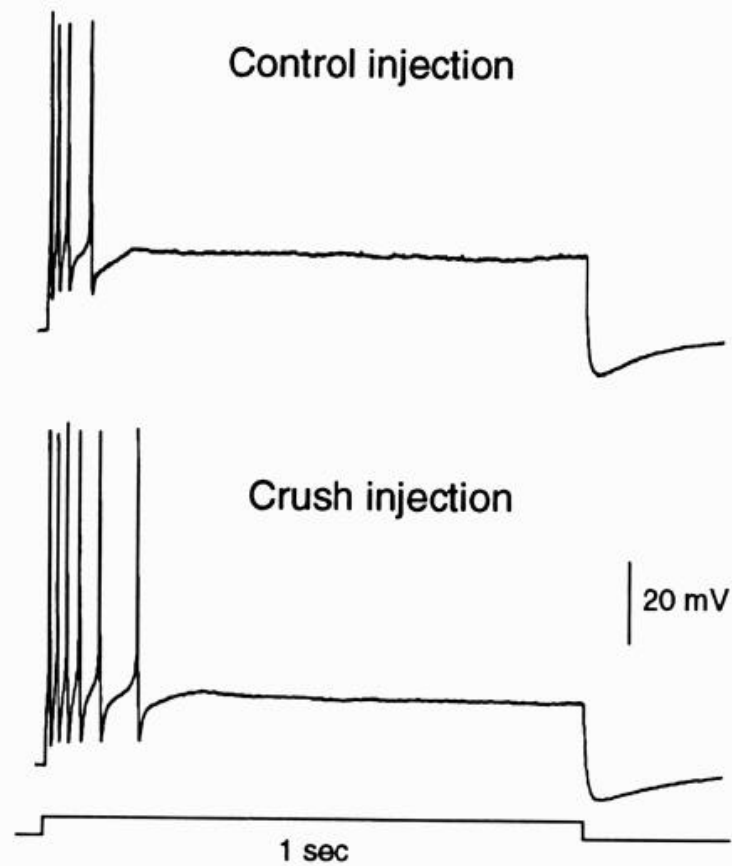

B.

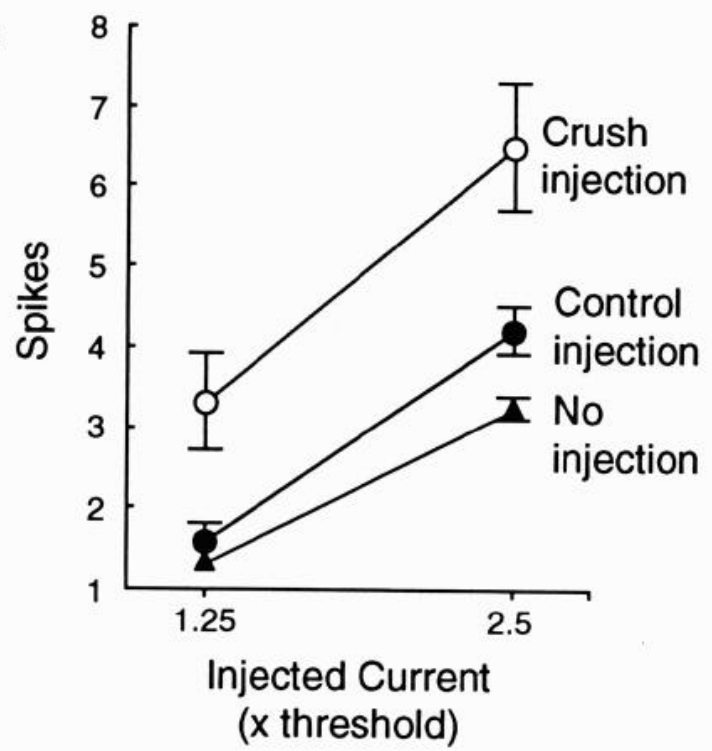

C.

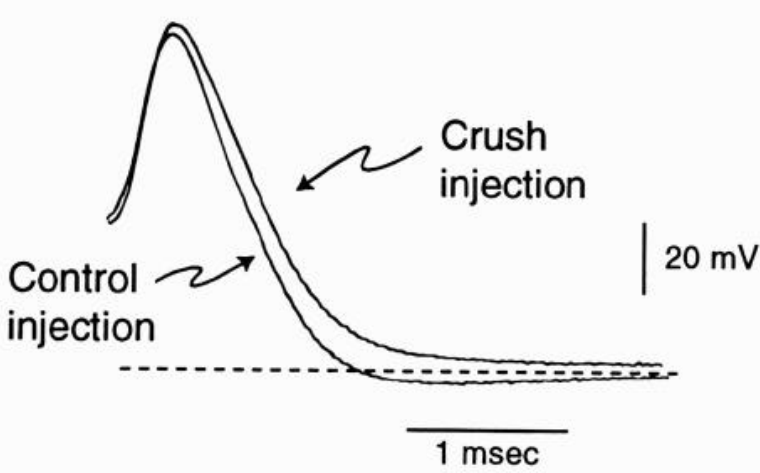

Figure 2. Long-term alterations in electrophysiological properties produced by injection of axoplasm from crushed nerves into sensory neuron somata. Control injections were identical except that axoplasm was collected from uncrushed nerves. $A$, Examples of repetitive firing in the sensory neuron soma $20 \mathrm{hr}$ after injection of control or crush axoplasm. Spikes were elicited by a I sec depolarizing pulse of constant current (set at $2.5 \times$ the current required to reach threshold during a $20 \mathrm{msec}$

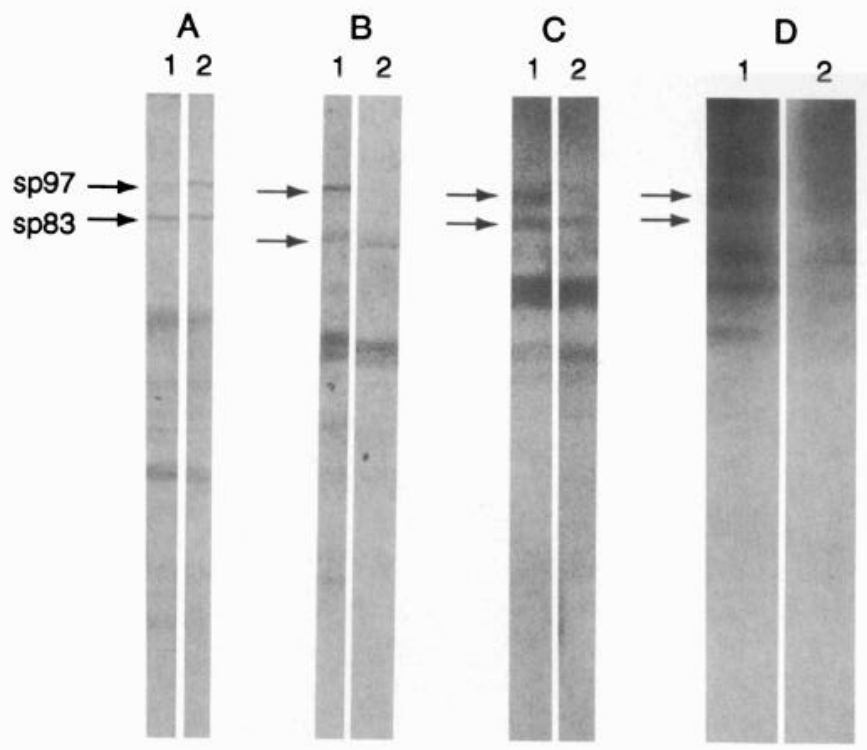

Figure 3. Distribution of sp-containing proteins in axoplasm. $A-C$, Western blots of axoplasm probed with the anti-sp antibody. Polypeptides were detected with HRP ( $A$ and $B$ ) or by chemiluminescence $(C)$. The position of sp97 and sp83 is indicated by the arrows. A, Comparison of axoplasm extruded from the retrograde side of ligations showing an enrichment of sp97 at the ligation on six crushed nerves (2) relative to six uncrushed nerves $(I)$. As shown in $B$, there was a marked reduction in the amount of sp97 in axoplasm at the crush site (2) relative to axoplasm behind the ligation (six nerves) $(I)$. The other sp-containing polypeptides were present in roughly equal amounts at both locations. When the ligation was omitted $(C)$, sp97 was greatly enriched in the cell bodies of the six sensory neuron clusters with crushed axons (I) relative to the six clusters with neurons whose axons were not injured (2). D, Autoradiograph of ${ }^{32} \mathrm{P}$-labeled proteins at the ligation from two crushed $(l)$ and two ligated nerves (2). Equal amounts of radiolabeled protein from the two sources were separated by SDS-PAGE. The proteins were transferred to nitrocellulose, which was then exposed to $\mathrm{x}$-ray film for $2 \mathrm{~d}$. The arrows show the positions of $\mathrm{sp} 97$ and $\mathrm{sp} 83$ determined from a Western blot on an accompanying gel. There was no phosphorylated band corresponding to $\mathrm{sp} 83$ under either condition.

synthesis. The identification of such signals would provide insight into how neuronal function and morphology are regulated by events in the axon periphery. In this article we have begun to test the hypothesis that some of the signals are intrinsic, constitutive proteins present in the axoplasm that communicate information about axon injury directly to the cell nucleus. We were in a favorable position to test this idea. First, we could obtain axoplasm free of glial cell and connective tissue proteins (Sherbany et al., 1984; Schmied et al., 1993). This enabled us to focus our search for the signal proteins on a relatively small and appropriate population of proteins. Second, the nerves that we used contain axons of the mechanosensory neurons whose reactions to injury have been well characterized (Walters et al., 1991; Dulin et al., 1994; Gunstream et al., 1994a,b). Finally, by as-

$\leftarrow$

pulse), $B$, Mean number of spikes evoked during I sec depolarizations at $1.25 \times$ and $2.5 \times$ spike threshold. Data for crush injection cells and control injection cells were collected from the same animals $(n=7$; see Table 1). Data for cells that were not injected came from animals $(n=6)$ from the same shipments that were examined at about the same time. $C$, Example of increase in soma action potential duration after injection of crush axoplasm. Duration was measured from the peak of the spike to the first intersection with the extrapolated initial resting potential. Summary results are presented in Table 1. 
suming that the previously defined retrograde axonal transport/ nuclear inport pathway transports the signals to the nucleus (Ambron et al., 1992; Schmied et al., 1993), we could use the antibody to $\mathrm{sp}$ to monitor the proteins that use this pathway.

\section{Evidence for positive molecular injury signals}

A positive injury signal is defined as an endogenous molecule that, when activated by injury, travels to the soma and induces a cellular reaction in the injured neuron. In contrast, negative injury signals result from an interruption of transport to the soma of molecules conveying information from peripheral targets or support cells. Although there is some evidence for the existence of positive injury signals in mammalian peripheral nerves (Singer et al., 1982; Soiefer et al., 1988), the evidence is indirect. Detection of protein injury signals in vertebrates is confounded by the complexity of their nerves and by the variability in the response of different neurons to injury (Titmus and Faber, 1990; Snow and Wilson, 1991). Such variability can be minimized, and the biological significance of injury reactions better understood, if axonal injury is studied in functionally identified neurons. Damage to axons of the 200 or so pleural mechanosensory neurons in Aplysia reliably causes well-defined alterations of several electrophysiological properties of the cell soma and synapse (Walters et al., 1991; Clatworthy et al., 1994). The alterations require gene transcription and protein synthesis (Gunstream et al., 1994b) and result in a long-lasting enhancement of the signalling effectiveness of the nociceptive sensory neurons. Evidence consistent with a role for positive injury signals in these cells was the finding that inhibitors of axonal transport (nocodazole and colchicine) block the crush-induced alterations and that the same inhibitors fail to produce the alterations when applied to uncrushed nerves (Gunstream et al., 1994a).

Because nocodazole is known to block the retrograde portion of the retrograde transport/nuclear import pathway (Ambron et al., 1992), sp-containing proteins that use this pathway to return to the nucleus after injury are primary candidates for injury signals. We found several sp-containing proteins in axoplasm from peripheral nerves and one, sp97, responded to a crush injury by undergoing retrograde transport to the cell soma (Fig. $3 C$ ). Because sp provides access to the nuclear import apparatus, it probably entered the nucleus. None of the other sp-containing proteins was affected by the crush. We do not know if there are axoplasmic proteins with other nuclear localization signals and, if so, whether they would have access to the retrograde transport/ nuclear import pathway. Comparison of axoplasm from crushed and uncrushed nerves by silver staining did not reveal any proteins that reversed transport after injury. Of course, if they were of low abundance like sp97, they could escape detection.

The experiments with nocodazole and colchicine (Ambron et al., 1992; Gunstream et al., 1994a) suggested that axoplasm from crush-injured nerves, but not uninjured nerves, would contain a molecular signal that induces the long-term electrophysiological alterations. This was substantiated when we injected axoplasm from crushed nerves into individual sensory neuron somata and found that it induced alterations very similar to those observed after axonal injury (Table 1, Fig. 2). These include increased repetitive firing, decreased AHP magnitude, and increased spike duration (cf. Walters et al., 1991; Clatworthy and Walters, 1994; Gunstream et al., 1994a). In addition, there was a suggestion of an increase in spike amplitude, which has recently been observed in these sensory neurons after axon injury (Dulin, 1994). The injection of crush axoplasm failed to induce the decrease in spike threshold that is usually seen after nerve crush. However, our sample size in the present study is much smaller than thosc used in the nerve crush studies, so it is premature to conclude that this effect is not induced by injection of crush axoplasm. We are now extending this approach to determine what other responses to injury might be triggered by retrogradely transported signal molecules. For example, Dulin et al. (1994) showed that crush injury induces regenerative and collateral sprouting of sensory neuron axons. When the axoplasm from crushed nerves that induced the electrical changes was injected into the cell bodies of Aplysia neurons in vitro, it promoted neurite outgrowth (Ambron et al., 1994). The growth was induced by a fraction of axoplasm that contains high molecular weight proteins, including sp97. Our experiments to date show that both the electrophysiological and growth sequelae of injury are elicited by constituents in axoplasm from injured nerves, but not from uninjured nerves. The fact that $s p 97$ is relatively abundant at the ligation from the crushed nerves relative to the noncrushed nerves suggests that this protein is involved in inducing these responses. Injury to the axons of the sensory neurons also induces long-term synaptic facilitation (Walters et al., 1991; Clatworthy and Walters, 1994), and it will be interesting to see if crush axoplasm can bring about this alteration as well.

\section{Convergence of signals for injury and learning}

An advantage to using Aplysia sensory neurons for studies of injury-induced plasticity is that there is a wealth of information about changes in these neurons associated with learning, specifically, with short- and long-term sensitization of defensive behavior following noxious stimulation (reviewed by Bailey and Kandel, 1993; Byrne et al., 1993; Hawkins et al., 1993; Walters, 1994). A notable finding therefore is that the enhanced repetitive firing found in the present study resembles learning-induced, long-term hyperexcitability in these same cells that was expressed as enhanced afterdischarge (Walters, 1987) and depressed outward currents (Scholz and Byrne, 1987) $24 \mathrm{hr}$ after strong cutaneous shock. Long-term changes in spike duration and AHP have not been explicitly studied during learning-related manipulations in Aplysia sensory neurons, but the short-term changes in these soma properties (e.g., Walters et al., 1983b; Hawkins et al., 1983; Klein et al., 1986; Dale et al., 1987; Baxter and Byrne, 1990) resemble those that we observed $20 \mathrm{hr}$ after injecting crush axoplasm. Furthermore, sensory neurons undergo long-term synaptic facilitation after learning and after axonal injury, and in both cases this facilitation involves some degree of axon growth (Bailey and Kandel, 1993; Ambron et al., 1994; Dulin et al., 1994). These parallels support the suggestion that some learning and memory mechanisms evolved from primitive mechanisms underlying adaptive reactions to neuronal injury (Walters et al., 1991; Walters, 1994). Moreover, they suggest that injury reactions and some forms of memory may share axoplasmic induction signals.

\section{Model for induction of long-term alterations by axoplasmic signal proteins}

Our data strongly point to intrinsic protein signals in axoplasm as triggers of long-lasting changes caused by injury to axons of the sensory neurons. Retrograde transport of such signals could also contribute to long-term memory induced by application of serotonin to synapses distant from the soma of the sensory neurons (Clark and Kandel, 1993; Emptage and Carew, 1993) where diffusion of the signal to the soma is unlikely. How could an 

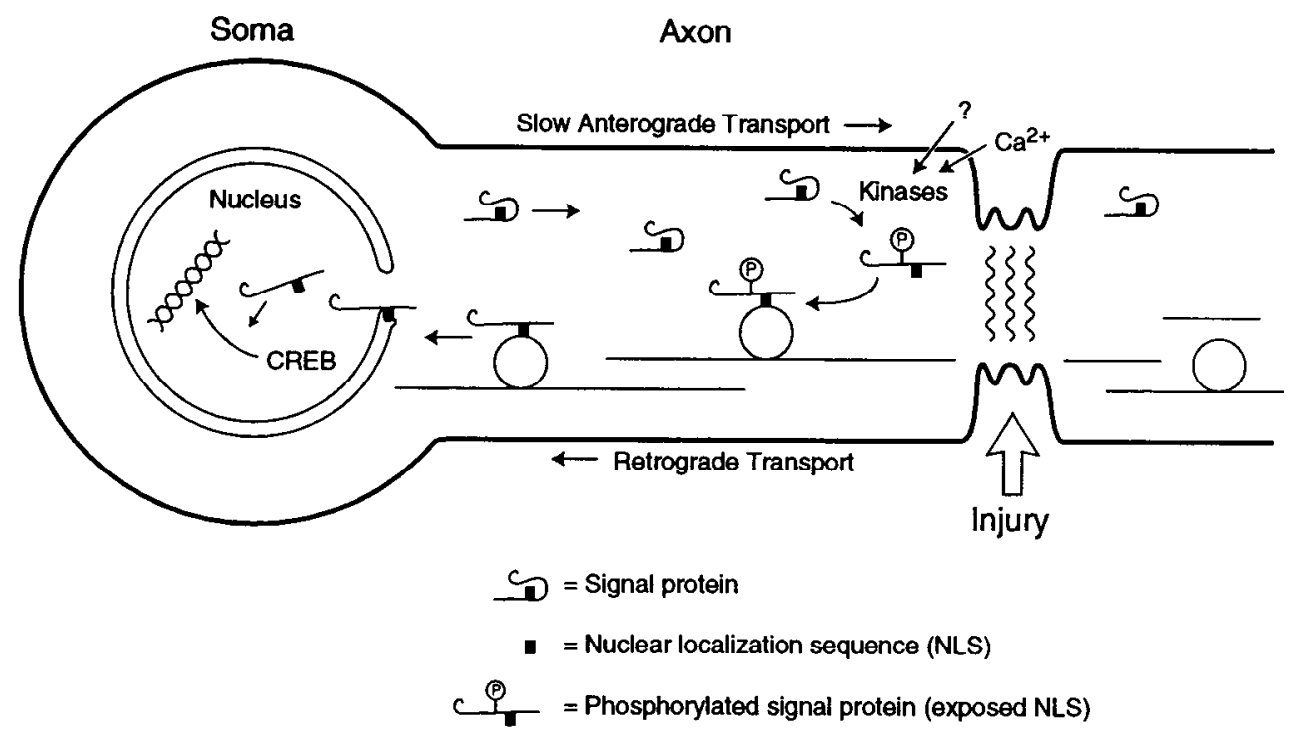

Figure 4. Retrograde transport/nuclear import model of axonal injury signals and potential memory signals. Second messengers released during injury cause phosphorylation (and/or other modifications) of the signal protein, revealing the NLS, which provides the signal protein access to the retrograde transport and nuclear import pathways. The same modification of signal proteins might be produced during learning via second messengers produced at presynaptic terminals, dendrites, or the cell soma. If convergence of injury signals and learning signals occurs early in the pathway, both kinds of events could regulate gene transcription by controlling the activity of nuclear transcription factors, such as the CREB family, that have been implicated in long-term memory in Aplysia (set text). CREB, cAMP response element binding protein. endogenous protein in the axon become a signal to the nucleus? While we do not have definitive evidence that sp97 causes electrophysiological or morphological responses to injury, this protein does, in many respects, behave like an injury signal. Thus, we can use what we know about this constituent to propose a preliminary, but testable, model of axoplasmic events that trigger long-term reactions to injury. We suggest that signal proteins containing a concealed NLS are dispersed throughout the neuron by slow axonal transport (Schmied et al., 1993) (Fig. 4). The sp contains but one example of a NLS, but others exist on cytoplasmic proteins and may also be present in the axon. During injury, increased levels of appropriate second messengers activate enzymes that phosphorylate, or otherwise modify the inactive signal proteins. The signal proteins unfold, exposing the NLS, which then provides access to the retrograde transport/ nuclear import pathway. The activated signal proteins are rapidly carried through the axon and imported into the nucleus where they trigger long-lasting alterations by regulating genes that control neuronal excitability, synaptic strength, and growth (see Ambron et al., 1994). NLS-containing signal proteins might also he activated by a learning-related increase in second messengers at synaptic terminals or in the cytoplasm of the soma. Whether the signal proteins for injury and learning are the same is an important unanswered question. One approach will be to see if NLS-containing proteins like sp97 regulate transcriptional factors, such as CREB, and immediate early genes, such as C/EBP that have been implicated in both memory induction and injury reactions (Dash et al., 1990; Herdegen et al., 1992, 1993; Kaang et al., 1993; Alberini et al., 1994).

\section{References}

Alberini CM, Ghirardi M, Metz. R, Kandel ER (1994) C/EBP is an immediate-early gene required for the consolidation of long-term facilitation in Aplysia. Neuron 76:1099-1114.

Aldskogius H, Arvidsson J, Grant G (1992) Axotomy-induced changes in primary sensory neurons. In: Sensory neurons: diversity, development, and plasticity (Scott SA, ed), pp 363-383. New York: Oxford UP.

Ambron RT, Schmied R, Huang CC, Smedman M (1992) A signal sequence mediates the retrograde transport of proteins from the axon periphery to the cell body and then into the nucleus. J Neurosei 12: $2813-2818$.

Ambron RT, Zhang X-P, Povelones MT (1994) Axoplasm extruded from injured nerves increases life expectancy and growth when injected into Aplysia neurons. Soc Neurosci Abstr 20:231.

Bailey CH, Kandel ER (1993) Structural changes accompanying memory storage. Annu Rev Physiol 55:397-426.

Baxter DA, Byrne JH (1990) Differential effects of cAMP and serotonin on membrane current, action potential duration, and excitability in somata of pleural sensory neurons of Aplysia. J Neurophysiol 64: 978-990.

Bernier L, Castellucci VF, Kandel ER, Schwartz, JH (1982) Facilitatory transmitter causes a selective and prolonged increase in adenosine 3',5'-monophosphate in sensory neurons mediating the gill and siphon withdrawal reflex in Aplysia. J Neurosci 2:1682-1691.

Bisby MA, Bulger VT (1977) Reversal of axonal transport at a nerve crush. J Neurochem 29:313-320.

Bulger VT, Bisby MA (1978) Reversal of axonal transport in regenerating nerves. J Neurochem 31:1411-1418.

Byrne JH, Zwartjes R, Homayouni R, Critz SD, Eskin A (1993) Roles of second messenger pathways in neuronal plasticity and in learning and memory. Insights gained from Aplysia. Adv Second Messenger Phosphoprotein Res 27:47-108.

Clark GA, Kandel ER (1993) Branch-specific heterosynaptic facilitation in Aplysia siphon sensory cells. Proc Natl Acad Sci USA 81: 2577-2581

Clatworthy AL, Walters ET (1994) Comparative analysis of hyperexcitability and synaptic facilitation induced by nerve injury in two populations of mechanosensory neurones of Ap/vsia californica. $\mathbf{J}$ Exp Biol 190:217-238.

Dale N, Kandel ER, Schacher S (1987) Serotonin produces long-term changes in the excitability of Aplysia sensory neurons in culture that depend on new protein synthesis. J Neurosci 7:2232-2238.

Dash PK, Huchner B, Kandel ER (1990) Injection of the cAMP-responsive element into the nucleus of Aplysia sensory neurons blocks long-term facilitation. Nature 345:718-721.

Dulin MF (1994) Long-term, injury-induced plasticity in Aplysia neurons: behavioral, electrophysiological, and morphological studies. $\mathrm{PhD}$ thesis, University of Texas.

Dulin MF, Billy AJ, Steffensen I, Walters ET (1994) Somatotopic organization and injury-induced sprouting in pleural sensory neurons of Aplysia. Soc Neurosci Abstr 20:230.

Eisenstatd M, Goldman JE, Kandel ER, Koike H, Koester J, Schwartz, JH (1974) Intrasomatic injection of radioactive precursors for studying transmitter synthesis in identified neurons of Aplysia californica. Proc Natl Acad Sci USA 70:3371-3375

Emptage NJ, Carew TJ (1993) Long-term synaptic facilitation in the absence of short-term facilitation in Aplysia neurons. Science 262: 253-256.

Frizell M, Mclean W. Sjostrand J (1976) Retrograde axonal transport of rapidly migrating labelled proteins and glycoproteins in regenerating peripheral nerves. J Neurochem 27:191-196; 
Grafstein B, Forman, DS (1980) Intracellular transport in neurons. Physiol Rev 60:1167-1283.

Greengard P, Valtorta PF, Czernik P, Benferati AJ (1993) Synaptic vesicle phosphoproteins and regulation of synaptic function. Science 259:780-785.

Gunstream JD, Castro GA, Walters ET (1994a) Retrograde transport of plasticity signals in Aplysia sensory neurons following axonal injury. $\mathbf{J}$ Neurosci, in press.

Gunstream JD, Castro GA, Walters ET (1994b) Injury-induced hyperexcitability of Aplysia sensory neurons depends on retrograde axonal transport, gene transcription, and protein synthesis. Soc Neurosci Abstr 20:230

Hawkins RD, Abrams TW, Carew TJ, Kandel ER (1983) A cellular mechanism of classical conditioning in Ap/ysiat activity-dependent amplification of presynaptic facilitation. Science 219:400-405.

Herdegen TH, Fiallos-Estrade CE, Schmid W, Bravo R, Zimmermann $M$ (1992) The transcription factors c-Jun, Jun D and CREB, but not FOS and KROX-24, are differentially regulated in axotomized neurons following transection of rat sciatic nerve. Mol Brain Res 14: $155-165$.

Herdegen TH, Bastmeyer M, Bahr M, Stuemer C, Bravo R, Zimmermann M (1993) Expression of JUN, KROX, and CREB transcription factors in goldfish and rat retinal ganglion cells following optic nerve lesion is related to axonal sprouting. J Neurobiol 24:528-543.

Kaang B-K, Kandel ER, Grant SGN (1993) Activation of cAMP-response genes by stimuli that produce long-term facilitation in Aplysia sensory neurons. Neuron 10:427-4.35.

Klein M, Hochner B, Kandel ER (1986) Facilitatory transmitters and cAMP can modulate accommodation as well as transmitter release in Aplysia sensory neurons: evidence for parallel processing in a single cell. Proc Natl Acad Sci USA 83:7994-7998.

Kristensson K, Olsson Y (1975) Retrograde transport of horseradish peroxidase in transected axons. II. Relations between rate of transfer from the site of injury to the perikaryon and onset of chromatolysis. J Neurocytol 4:653-661.

Leah J, Herdegen T, Kovary K, Bravo R (1991) Selective expression of JUN proteins following peripheral axotomy and block of axonal transport in the rat: evidence for a role in regeneration process. Brain Res 566:198-208.

Morgan JI, Curran T (1991) Stimulus-transcription coupling in the nervous system: involvement of the inducible proto-oncogenes fos and jun. Annu Rev Neurosci 14:421-451.

Nja A, Purves D (1978) The effects of nerve growth factor and its antiserum on synapses in the superior cervical ganglion of the guineapig. J Physiol (Lond) 277:55-75.

Schmidt RE, Yu MJ, McDougal DB Jr ( 1980) Turnaround of axoplasmic transport of selected particle-specific enzymes at an injury in control and diisopropylphosphorofluoridate-treated rats. J Neurochem $35: 641-652$.

Schmied R, Huang CC, Zhang X, Ambron D, Ambron RT (1993) Endogenous axoplasmic proteins and proteins containing nuclear localization signal sequences use the retrograde axonal transport/nuclear import pathway in Aplysia neurons. J Neurosci 13:4064-4071.
Scholz KP, Byrne JH (1987) Long-term sensitization in Aplysia: biophysical correlates in tail sensory neurons. Science 235:685-687.

Sheng M, Greenberg ME (1990) The regulation and function of c-fos and other immediate early genes in the nervous system. Neuron $4: 477-485$.

Sherbany AA, Ambron RT, Schwartz JH (1984) Characterization of glycolipids synthesized in an identified neuron of Aplysia californica. J Neurosci 4:1875-1883.

Singer PA, Mehler S, Fernandez HL (1982) Blockade of retrograde axonal transport delays the onset of metabolic and morphologic changes induced by axotomy. J Neurosci 2:1299-1306.

Smith RS (1988) Studies on the mechanism of the reversal of rapid organelle transport in myelinated axons of Xenopus laevis. Cell Motil Cytoskeleton 10:296-308.

Smith RS, Snyder RE (1991) Reversal of rapid axonal transport at a lesion; leupeptin inhibits reversed protein transport, but does not inhibit reversed organelle transport. Brain Res 552:215-227.

Snow PJ, Wilson P (1991) Plasticity in the somatosensory system of developing and mature mammals--the effects of injury to the central and peripheral nervous system. Berlin: Springer

Soiefer AI, Moretto A, Spencer PS, Sabri MI (1988) Axotomy-induced ornithine decarboxylase activity in the mouse dorsal root ganglion is inhibited by the vinca alkaloids. Neurochem Res 13:1169-1173.

Titmus MJ, Faber, DS (1990) Axotomy-induced alterations in the electro- physiological characteristics of neurons. Prog Neurobiol 35:151.

Traynor P, Dryden WF, Smith PF (1992) Trophic regulation of action potentials in bullfrog sympathetic neurones. Can J Physiol Pharmacol 70:826-834

Vendrell M, Curran T, Morgan JI (1993) Glutamate, immediate-early genes, and cell death in the nervous system. Ann NY Acad Sci 679: $132-141$.

Walters ET (1987) Multiple sensory neuronal correlates of site-specific sensitization in Aplysia. J Neurosci 7:408-417.

Walters ET (1994) Injury-related behavior and neuronal plasticity: an evolutionary perspective on sensitization, hyperalgesia and andigesia. Int Rev Neurobiol 36:325-427.

Walters ET, Byrne JH, Carew TJ, Kandel ER (1983a) Mechanoafferent neurons innervating the tail of Aplysia. I Response properties and synaptic connections. J Neurophysiol 50:1522-1542.

Walters ET, Byrne JH, Carew TJ, Kandel ER (1983b) Mechanoafferent neurons innervating the tail of Aplysia. II Modulation by sensitizing stimulation. J Neurophysiol 50:1543-1559.

Walters ET, Alizadeh H, Castro EA (1991) Similar neuronal alterations induced by axonal injury and learning in Aplysia. Science 253:797799.

Walters ET, Dulin MD, Zhang X-P, Ambron RT (1994) Hyperexcitability induced by injecting Aplysia neurons with molecules transported to the soma after axonal injury suggests a conserved mechanism for injury reactions and memory. Soc Neurosci Abstr 20:231.

Watson WE (1968) Observation on the nucleolar and total body nucleic acid of injured nerve cells. J Physiol (Lond) 196:655-676.

Wu W, Mathew TC, Miller, FD (1993) Evidence that the loss of homeostatic signals induces regeneration-associated alteration in neuronal gene expression. Dev Biol 158:456-466 